\title{
In-Season Biomass Estimation of Oilseed Rape (Brassica napus L.) Using Fully Polarimetric SAR Imagery
}

\author{
Hao Yang ${ }^{1,2,3}$ • Guijun Yang ${ }^{1, *}$. Rachel Gaulton ${ }^{2}$. Chunjiang Zhao ${ }^{1, *}$. Zhenhong Li $^{2}$. James \\ Taylor $^{4}$. Daniel Wicks ${ }^{5}$. Andrea Minchella ${ }^{5}$. Erxue Chen ${ }^{3}$. Xinting Yang ${ }^{1}$
}

\begin{abstract}
Accurate estimation of crop biophysical and biochemical parameters during crop growing seasons is essential for improving site-specific management and yield estimation. The potential ability of fully polarimetric SAR (Synthetic Aperture Radar) data in estimating aboveground biomass of oilseed rape was investigated in this study. The temporal profile of different scattering intensity and polarimetric features during the entire growing season was identified with ground measurements. A polarimetric feature, relying on the polarimetric decomposition method, was put forward to estimate the biomass of oilseed rape. Validation results revealed great potential with a determination coefficient $\left(\mathrm{R}^{2}\right)$ of 0.85 , Root Mean Squared Error (RMSE) of $41.6 \mathrm{~g} / \mathrm{m}^{2}$, and Relative Error (RE) of $28.5 \%$ for dry biomass, and an $\mathrm{R}^{2}$ of 0.76 , RMSE of $527.4 \mathrm{~g} / \mathrm{m}^{2}$ and RE of $28.6 \%$ for fresh biomass. Moreover, the use of full polarization SAR data was compared with single and dual polarization SAR data. The results suggest that when full polarization SAR data is available, a simpler model, higher saturation point and better accuracy can be achieved in biomass estimation of oilseed rape, which highlights the importance and value of polarimetry information in quantitative crop monitoring. This study provides guidelines for in-season monitoring of crop growth parameters with SAR data, which further improves crop monitoring capability in adverse weather conditions.
\end{abstract}

Keywords: RADARSAT-2; biomass; polarimetric features; polarimetric decomposition; rapeseed

Contact: Guijun Yang, Chunjiang Zhao

yanggj@nercita.org.cn, zhaocj@ nercita.org.cn

1 Beijing Research Center for Information Technology in Agriculture, Beijing Academy of Agriculture and Forestry Sciences, Beijing 100097, China

2 School of Civil Engineering and Geosciences, Newcastle University, Newcastle upon Tyne, NE1 7RU, UK

3 Institute of Forest Resource Information Techniques, Chinese Academy of Forestry, Beijing 100091, China

4 School of Agriculture, Food and Rural Development, Newcastle University, Newcastle upon Tyne, NE1 7RU, UK

5 Satellite Applications Catapult, Didcot, Oxfordshire, OX11 0QR, UK

\section{Introduction}


Oilseed rape (Brassica napus L.) is produced as a source of edible vegetable oils, biodiesel and animal feeds (Ren et al. 2015) and is the most important oil crop in China. The Food and Agriculture Organization of the United Nations (FAO) reports that China is the largest oilseed rape cultivated region in the world, in terms of both planting area and yield (FAO 2013). Accurate estimation of crop biophysical and biochemical parameters during the growing season is essential for improving sitespecific management and yield estimation (Jin et al. 2015), among which above-ground biomass is the most important indicator for crop yield (Tilly et al. 2015). Therefore, quantitative monitoring of oilseed rape biomass across large areas will not only provide information for crop growth and precision agriculture, but also support production forecasts and encourage competition in the international edible oil market.

Crop biomass is traditionally estimated through destructive and time-consuming in situ methods, which are difficult to conduct when crops cover large regions (Jin et al. 2015). Remote sensing methods offer several advantages for monitoring biomass in a timely within-season manner and a number of studies have developed and validated methods to estimate biomass using optical imagery (Hosseini et al. 2015, Kross et al. 2015, Bendig et al. 2014, Hunt et al. 2005, Ahamed et al. 2011). A review of remote sensing methods for assessing biomass is given by Ahamed et al. (2011). Although these studies have demonstrated the successful retrieval of biomass, almost all of them are based on optical remote sensing, which faces the problem of frequent cloud or haze cover. Bad weather limits the acquisition of high quality optical remote sensing data. It further hampers the frequency of data update, which is vital given that crop vegetation grows and changes rapidly during certain growth stages. In addition, saturation is a common problem in optical data for dense crop coverage, because the vegetation indices lose sensitivity when the leaf area index (LAI) exceeds 2-5 (Gao et al. 2013, Ahamed et al. 2011).

Synthetic aperture radar (SAR) imagery provides a complementary and unique characterization of vegetation relative to that achieved with optical data, making its use of particular significance and interest for crop monitoring (McNairn et al. 2014, 2009, McNairn and Brisco 2004). Due to wavelengths being in the microwave region and are actively generated by the sensor itself, SAR systems are unaffected by the presence of clouds/hazes and are therefore able to collect earth surface data irrespective of weather or light conditions. More importantly, due to its penetration ability, SAR can penetrate crop canopies and has potential in overcoming the saturation limitations of optical data for dense vegetation measurement. These advantages, along with the sensitivity of microwave scattering to soil and vegetation characteristics, such as structure, moisture content and biomass, have led researchers to investigate the application of SAR for agriculture monitoring (Yang et al. 2015, McNairn and Brisco 2004, Lopez-Sanchez and Ballester-Berman, 2009). Despite these advantages, SAR images are affected by the sensors imaging geometry and radiation mechanism as well as speckle effects which present challenges in data interpretation.

The potential of radar backscatter to estimate crop growth parameters has been studied for many crop types, including paddy rice (Inoue et al. 2014, Lopez-Sanchez et al 2014), wheat (Kim et al. 2014, Jin et al. 2015), barley (Fontanelli et al. 2013, Cable et al. 2014), sugarcane (Baghdadi et al. 2009), maize and soybean (Gao et al. 2013, Jiao et al. 2011), using airborne and/or space-borne sensors (Tanase et al. 2014). A number of retrieval strategies have been adopted including empirical models (Wiseman et al 2014, Jin et al. 2015, Palosica 2002) that related radar backscatter to crop biophysical parameters, semiempirical approaches (Beriaux et al. 2015, 2013, Lin et al. 2009), which have frequently been based on the water cloud model (Attema and Ulaby, 1978), and more recently, numerical models (Zhang et al. 
2014, Jia et al. 2014, 2013) that are based on machine learning algorithms or complex vegetation scattering models. Although a consensus on the best models for biomass retrieval is yet to emerge, most of these models make use of SAR scattering intensity information, which is based on single polarization or dual polarization channels.

Polarimetric information is a unique property of SAR observations that has not received deserved attention in quantitative crop monitoring. Fully or quad polarimetric (quad-pol) SAR systems have the advantage of enabling a complete description of the scattering process, thus providing information on the entire scattering matrix that can be decomposed into surface, volume, and double-bounce contributions (Cloude 2009, Lee and Pottier, 2009). The quad-pol system, alternatively transmitting two orthogonal polarizations and receiving in both polarizations simultaneously, has many advantages over single polarization SAR systems. With increased access to polarimetric SAR data, i.e., RADARSAT2(Canada, launch 2007), TerraSAR-X(Germany, launch 2007), ALOS PALSAR(Japan, launch 2006/2014), Sentinel-1(ESA, launch 2014), and GF-3(China, launch 2016), the use of polarimetric information becomes feasible for crop monitoring. Most polarimetric decomposition studies have been undertaken for classification purposes (McNairn et al. 2014; Qi et al. 2015) rather than direct biomass estimation (Tanase et al. 2014). To the best knowledge of the authors, the use of specific scattering components for model parameterization and direct biomass estimation has only been investigated recently with great uncertainty (Wiseman et al 2014, Tanase et al. 2014, Zhang et al. 2012). Quantitative crop biomass estimation from fully polarimetric SAR data remains to be explored.

Therefore, the objectives of this study were to: (1) evaluate whether fully polarimetric data is necessary for quantitative crop monitoring, as opposed to single or dual polarimetric data; (2) develop an operational method for the estimation of biomass of oilseed rape (Brassica napus L.); and (3) investigate the use of polarimetric target decomposition components for direct model parameterization. Relevant issues regarding crop biomass retrieval error are also discussed.

\section{Materials and methods}

\section{Study Area}

The study region is located in the Shangkuli agricultural area $\left(50^{\circ} 17^{\prime}\right.$ to $50^{\circ} 23^{\prime}$ lat. $\mathrm{N} ; 120^{\circ} 46^{\prime}$ to $120^{\circ} 53^{\prime}$ long. E), Hailar City, Inner Mongolia, China (Fig. 1). This area, typical of agricultural land use for Northeast China, lies on the transition zone between forest and prairie (northwest of the Greater Khingan Mountains and north of the Hulunbuir steppe). It has a cold temperate continental monsoon climate, i.e., cold and dry in the long winter and warm and wet in the short summer, supporting one arable harvest per year. The soil is classified as Leached Chernozem with sand clay silt texture ( sand = $5.86 \%$, clay $=42.08 \%$, silt $=52.06 \%$, based on three soil samples collected in the study area. Topographic variations are minimal with slopes generally less than $1 \%$ in arable areas. Approximately $90 \%$ of the farmland is used for annual crop cultivation, principally oilseed rape and spring wheat. This farm is managed by a single entity. Crops are usually sown from May to June, reaching maturity in the middle of August, and harvested in September. The arable area extends over 3000 ha, with simple sowing patterns and homogeneous field parcels. A set of 88 oilseed rape fields was selected for this study, all sown with a near constant east-west row direction. The area of fields ranges from 3.3 to 47.0 ha, with a median of 18.6 ha. 


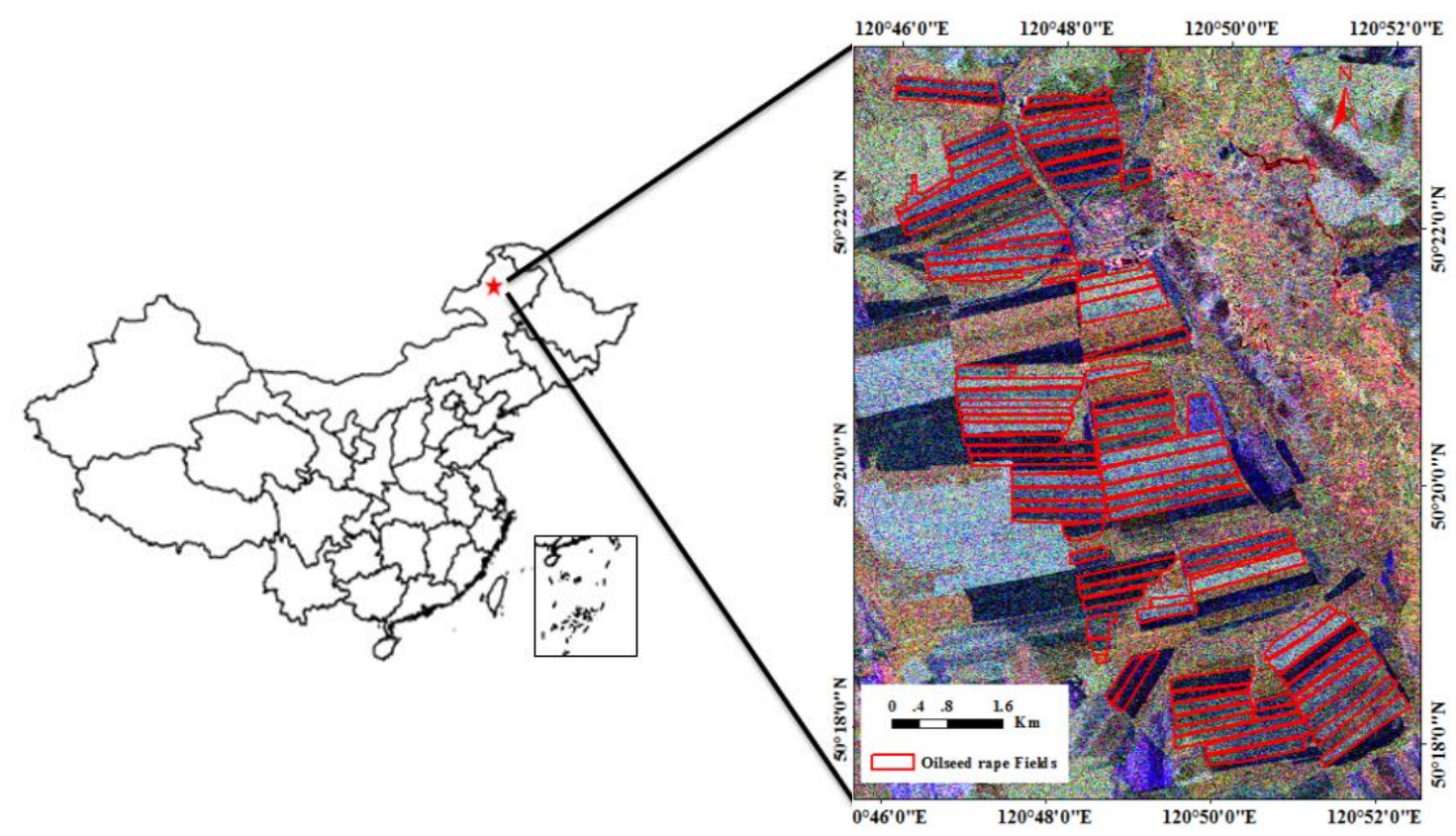

Fig. 1 Location of the Shangkuli agricultural area and the oilseed rape fields; Background: Paulibasis RGB image of RADARSAT-2, acquired on 16 June 2013.

\section{SAR data and ground truth data}

Canada's next-generation commercial radar satellite, RADARSAT-2 is an Earth observation satellite, launched in December 2007 for the Canadian Space Agency by Starsem. RADARSAT-2 carries a Cband $(\sim 5.3 \mathrm{GHz})$ SAR sensor with multiple polarization modes, including a fully polarimetric mode in which HH, HV, VV and VH polarized data are acquired (H-Horizontal, V-Vertical, i.e., HV denotes transmitting a Horizontal linear polarization and receiving a Vertical linear polarization). RADARSAT2 is a follow-on to RADARSAT-1. It has the same orbit (798 km altitude sun-synchronous orbit) and 24 days repeat cycle.

Five consecutive fully polarimetric RADARSAT-2 images were acquired in repeat pass with 24-day intervals during the growing season in 2013. All of them were acquired with the same imaging mode, including beam mode, incidence angle and orbit direction, in order to build a time series in the most consistent way (Table 1). Their acquisition periods cover the most critical growth stages of the crop, from sowing to harvest, as shown in Table 2. Original RADARSAT-2 images were provided in single look complex (SLC) format with pixel spacing of $4.73 \mathrm{~m}$ and $4.96 \mathrm{~m}$ in azimuth and slant range directions, respectively.

Table 1 Main parameters of RADARSAT-2 images.

\begin{tabular}{cc}
\hline Parameter & Values \\
\hline Imaging Mode & Fine Quad Polarization \\
Center frequency & $5.405 \mathrm{GHz}$ \\
Incidence angle & $37.4^{\circ}-38.8^{\circ}$ \\
Resolution & $7.6 \mathrm{~m} \times 5.2 \mathrm{~m}$ (diffrent from \\
& pixel spacing) \\
\hline
\end{tabular}




$\begin{array}{cc}\text { Swath width } & 25 \mathrm{~km} \\ \text { Orbit direction } & \text { Ascending } \\ \text { Beam mode } & \text { FQ18 } \\ \text { Acquired Time } & \text { UTC } 09: 47: 33\end{array}$

Table 2 Acquisition dates of five RADARSAT-2 images and corresponding phenological stages of oilseed rape.

\begin{tabular}{cc}
\hline Acquisition Dates & Principal Growth Stage \\
\hline 23 May 2013 & Germination (0) \\
16 June 2013 & Leaf development (1) and formation of \\
& side shoots (2) \\
10 July 2013 & Stem elongation (3), inflorescence \\
& emergence (5), and flowering (6) \\
03 August 2013 & Development of fruit (7) \\
27 August 2013 & Ripening (8) and senescence (9) \\
\hline
\end{tabular}

During the seeding period in 2013, the sowing dates of all the 88 fields in this study site were recorded. The sowing period lasted from 8 May to 31 May 2013, with 17 different sowing dates and 24 days duration. Five synchronous ground measurement campaigns were carried out within $\pm 24 \mathrm{~h}$ of each RADARSAT-2 acquisition time. In each campaign, the same 11 14 representative oilseed rape fields were surveyed from the 88 fields. Quantitative agronomic and biophysical parameters were measured, including leaf area index (LAI), plant height, surface soil moisture, above-ground biomass (fresh and dry weight per square meter) and vegetation water content. LAI $\left(\mathrm{m}^{2} / \mathrm{m}^{2}\right)$ was randomly measured at three sample sites within each field using a LI-COR LAI-2200 instrument (https://www.licor.com/env/products/leaf_area/LAI-2200C ). The top $76 \mathrm{~mm}$ soil volumetric water content $\left(\mathrm{m}^{3} / \mathrm{m}^{3}\right)$ was also randomly measured at three sample sites within each field using the FieldScout TDR 300 (https://www.specmeters.com/soil-and-water/soil-moisture/fieldscout-tdr-meters/ ) Soil Moisture Meter in High Clay mode (since the clay content in this site is high) after calibration. At each of the three sample sites, five soil moisture readings were taken resulting in 15 moisture readings per field. One representative biomass sample was collected within the field for each field. All the aboveground vegetation in a square of $0.5 \mathrm{~m} \times 2$ rows was harvested and weighed. The row distance was measured to obtain the sample area. All biomass samples were dried in an oven at $95{ }^{\circ} \mathrm{C}$ for at least $48 \mathrm{~h}$ and then reweighed, providing dry biomass $\left(\mathrm{g} / \mathrm{m}^{2}\right)$ as well as plant water content ((wet-dry)/wet, $\left.\mathrm{g} / \mathrm{g}\right)$. During the ground surveys, photographs of the crop development were taken as a reference relative to the key growth stages for oilseed rape (Fig. 2). Daily precipitation, air temperature, humidity and wind data, and other meteorological parameters were recorded by an automatic meteorological station (MidWest, WPH1-PH-6, http://detector.midwest-g.com/ WPH1-PH-6.html). 


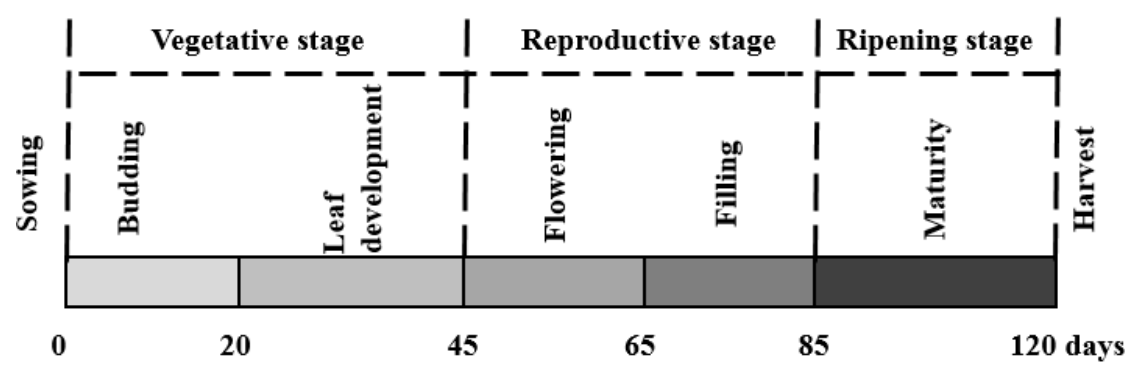

Fig. 2 Typical growth stages of oilseed rape

\section{SAR data processing}

RADARSAT-2 data were provided in single look complex (SLC) products as a Sinclair matrix for each slant range pixel. First, radiometric calibration was carried out using a look-up table in the product file, to transform the digital number of each pixel into backscattering coefficient. Secondly, a $5 \times 5$ Boxcar speckle filter was applied to suppress noise and increase the equivalent number of looks. Thirdly, the data were ortho-rectified based on the Range-Doppler model (Gens et al. 2013). The 30-m Digital Elevation Model (DEM) data (https://lpdaac.usgs.gov/dataset_discovery/aster/aster_products_table lastgtm) were used to simulate the SAR image according to its imaging geometry and available orbit information from the metadata, and the real SAR image was matched to the simulated image, warping to the DEM co-ordinate system. After the terrain correction, the datasets were geocoded into Universal Transverse Mercator (UTM) map projection (Zone North 51) (Yang et al. 2014).

\section{Polarimetric Decomposition methods}

Polarimetric decomposition is the most effective method for extracting polarimetric features and physical information from observed scenes (Lee and Pottier, 2009). There are two categories of methods: eigenvalue-based and model-based polarimetric scattering decomposition (Cloude 2009). In particular, the Cloude-Pottier (Cloude and Pottier, 1997) and Freeman-Durden (Freeman and Durden, 1998) decompositions are commonly cited and applied to agricultural applications.

The Cloude-Pottier method decomposes the coherency matrix, a statistical representation of the pixel information from a polarimetric data set, into different eigenvectors and eigenvalues that classify and describe the primary scattering mechanisms. Physical information provided by the decomposition is characterized by 3 variables: entropy, alpha angle and anisotropy. The variable entropy describes the scattering randomness and is theoretically associated with the depolarization effects of target features, ranging from 0 to 1 . It represents the randomness of the scattering process from isotropic scattering $($ entropy $=0)$ to totally random scattering $($ entropy $=1)$. The variable alpha angle indicates the dominant scattering mechanisms, ranging from $0^{\circ}$ to $90^{\circ}\left(0^{\circ}\right.$ indicating totally surface scattering, $90^{\circ}$ indicating totally double bounce scattering, and $45^{\circ}$ indicating totally volume scattering). The variable anisotropy, which is the counterpart of entropy, represents the relative power of the second and third scattering mechanisms. In contrast, the Freeman-Durden method decomposes the backscatter response into three categories of basic scattering components: volume scattering ( $\mathrm{Vol}$ ), modeled as a set of randomly oriented dipoles; double-bounce scattering $(\mathrm{Dbl})$, modeled by a dihedral corner reflector; and odd 
scattering $(O d d)$, modeled by a first-order Bragg surface scatter. These six polarimetric features will be utilized for exploring the polarimetric scattering mechanism of oilseed rape. It is noted that each parameter was averaged at the field level to better overcome the intrinsic speckle effect. There was no influence from anything other than crop when field averaging, e.g., a power-line.

Moreover, it is generally understood that volume scattering usually comes from crop vegetation contribution in agricultural scenes, while odd scattering comes from soil contribution. The type of dominant scattering mechanism, however, will change as the crop develops. For example, in early stages of growth, soil will provide the dominant contribution. In this study, polarimetric ratios were also examined based on polarimetric scattering components: $\mathrm{Vol} /(\mathrm{Odd}+\mathrm{Dbl})$, or $\mathrm{Vol} / \mathrm{Odd}$.

\section{Data analysis methods}

The temporal profile of scattering intensity features and polarimetric features during the entire growing season was analyzed as a function of Days After Sowing (DAS) based on all 88 oilseed rape fields. It should be noted that DAS can be easily transformed into thermal time, such as accumulated GDDs (Growing Degree Days), which is more meaningful from an agronomy perspective, related directly to crop phenological phases (Raoofi and Javadi, 2014). Therefore the temporal results were also investigated when GDDs was used as the timeline. Since there were 17 different sowing dates for all the 88 fields, relying on different sowing dates (17 dates) and five SAR acquisition, a near-continuous profile $(17 \times 5=85$ observation dates $)$ was obtained in terms of DAS, covering nearly $80 \%$ of the growing days over the entire 2013 season.

These features were evaluated to find potential indicators for crop biomass. The evaluation criterion for these indicators was whether the temporal profile curve was smooth. If the curve is smooth, simple methods can be used to estimate biomass, such as linear, logarithmic, exponential or higher degree polynomials models, which will meet the requirements of operational applications.

When just single polarization channel data was available, three polarization channels $(\mathrm{HH}, \mathrm{HV}$, and VV) were investigated, respectively. When dual polarization channel data was available, considering all the meaningful combination of two channels, three indicators were selected: HH/VV, HH/HV, and VH/VV (note HV $\approx$ VH). The Polarization Discrimination Ratio (PDR) (Singh 2006) was also examined given that it has demonstrated its capability of monitoring crop growth parameters, according to the following expression:

$$
P D R=\frac{\sigma_{H H}-\sigma_{V V}}{\sigma_{H H}+\sigma_{V V}}
$$

In Eq.(1), $\sigma_{H H}$ and $\sigma_{V V}$ indicate the radar backscatter coefficient of $\mathrm{HH}$ and $\mathrm{VV}$ polarization, respectively.

When quad polarization channel data were available, the two decomposition methods described above were applied to generate six polarimetric parameters. In parallel, the Radar Vegetation Indices (RVI), which have been widely used for vegetation monitoring, (given by Kim et al. 2014) were also investigated:

$$
R V I=\frac{8 \sigma_{H V}}{\sigma_{H H}+\sigma_{V V}+2 \sigma_{H V}}
$$


In Eq.(2), $\sigma_{H H}, \sigma_{V V}$ and $\sigma_{H V}$ indicate the radar backscatter coefficient of $\mathrm{HH}, \mathrm{VV}$ and $\mathrm{HV}$ polarization, respectively.

Then, crop biomass was estimated with the SAR indicators based on a regression model. The estimation result was validated by leave-one-out cross-validation methods. In this approach, one field was excluded from each model fit and oilseed rape biomass was predicted using the remaining fields. The performance was evaluated by the coefficient of determination $\left(\mathrm{R}^{2}\right)$, root mean square error (RMSE) and relative error ( $\mathrm{RE}$ in \%).

$$
\begin{aligned}
& R M S E=\sqrt{\frac{1}{n} \sum_{i=1}^{n}\left(y_{i}-\hat{y}_{i}\right)^{2}} \\
& R E[\%]=\frac{100}{\bar{y}_{i}} * R M S E
\end{aligned}
$$

where $y^{i}, \hat{y}_{i}$, and $\bar{y}_{i}$ are measured values, predicted values and the mean of the measured values, respectively, and $n$ is the number of observations.

\section{Results and discussion}

\section{Temporal profile of field observations}

The results of field observations are presented with DAS used as the timeline. Due to 17 different sowing dates over the 88 fields, the status of 17 different oilseed rape at each satellite overpass was observed. Examples of in situ ground photos are shown in Figure 3. It was found that the soil background, stems, leaves, flowers and pods change with DAS, which can be used to explain the change of backscattering response. The temporal profile of ground measurements, including fresh biomass, dry biomass, plant height, and vegetation water content, are presented in Figure 4. The dry biomass (Fig. 4a) increased steadily with DAS, and reached a peak at the end of the crop cycle. The fresh biomass (Fig. 4b) increased until the crop entered into the ripening stage when vegetation water content (VWC) decreased sharply (Fig. 4d). The plant height (Fig. 4c) increased at the early stages and then stopped. Some fields in the study site were harvested on 27 August, so only a few biomass samples were collected. The temporal profile of ground measurements meets the general agronomic trend. Moreover, since the precipitation can cause changes in SAR scattering, the meteorological data was investigated. Daily precipitation and mean air temperature recorded during the 2013 growing season are shown in Figure 5. Note that the cumulative precipitation during the seven days before each satellite acquisition date were $6.4 \mathrm{~mm}, 45.3 \mathrm{~mm}, 73.8 \mathrm{~mm}, 180.2 \mathrm{~mm}$ and $4.4 \mathrm{~mm}$, respectively. There was heavy rain before the field campaign on 3 August 2013. 

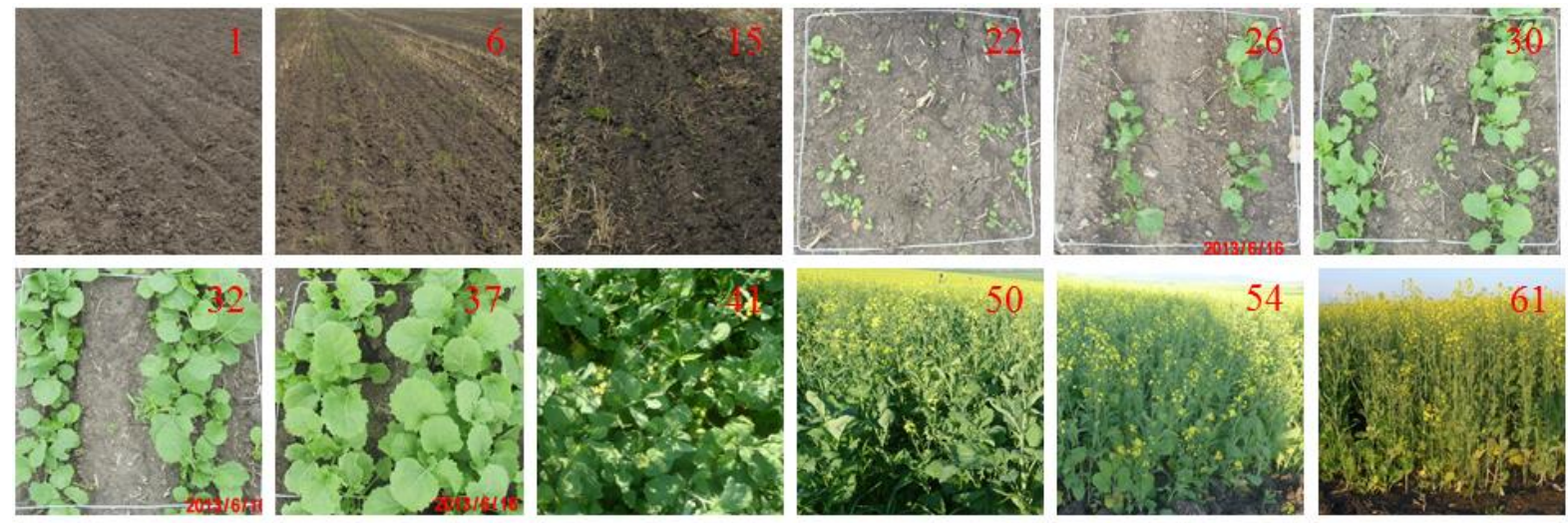

69
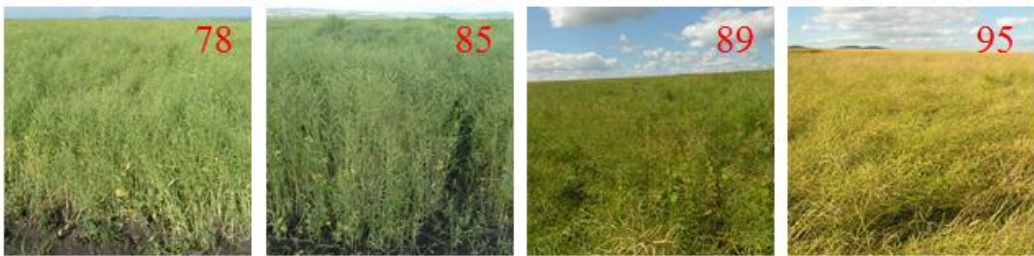

110

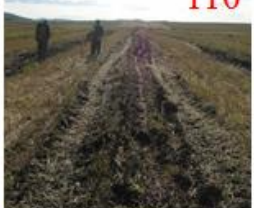

Fig. 3 Typical oilseed rape fields at different DAS. Note that DAS is shown in the upper-right corner of each image.
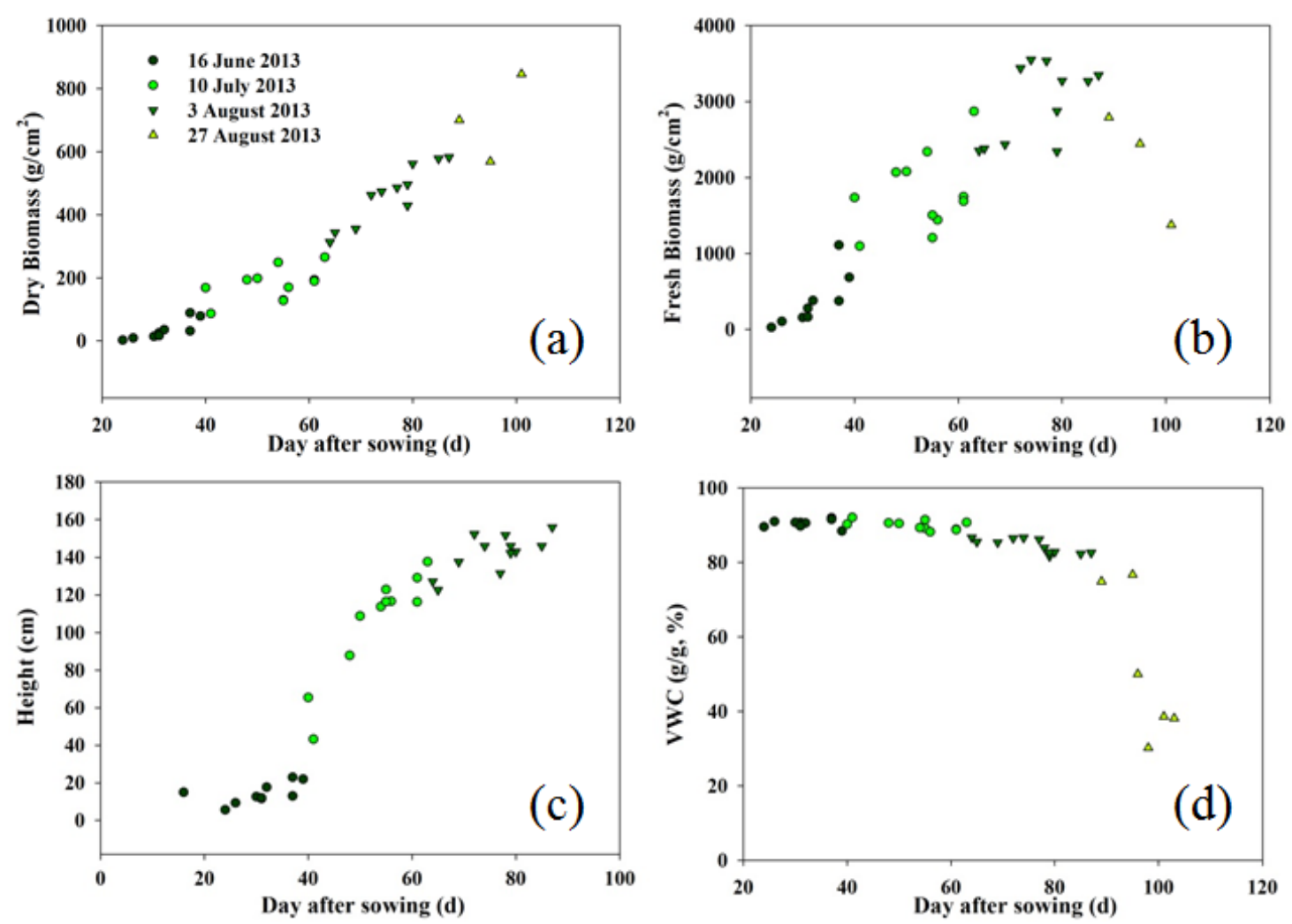

Fig. 4 Ground measurements of different parameters shown according to DAS. (a) Dry biomass, (b) Fresh biomass, (c) Height, and (d) Vegetation water content. 


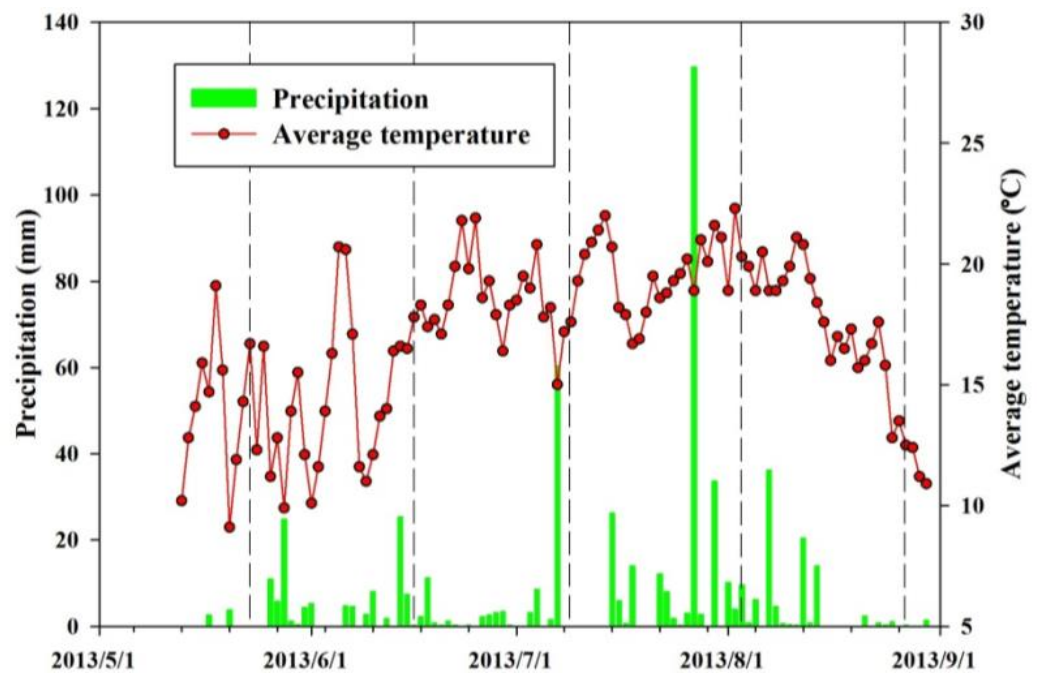

Fig. 5 The daily precipitation and average temperature (from 13 May-30 August 2013); the five vertical dash lines indicate SAR observation dates (23 May, 16 June, 10 July, 3 August, 27 August).

\section{Temporal scattering behavior based on intensity features}
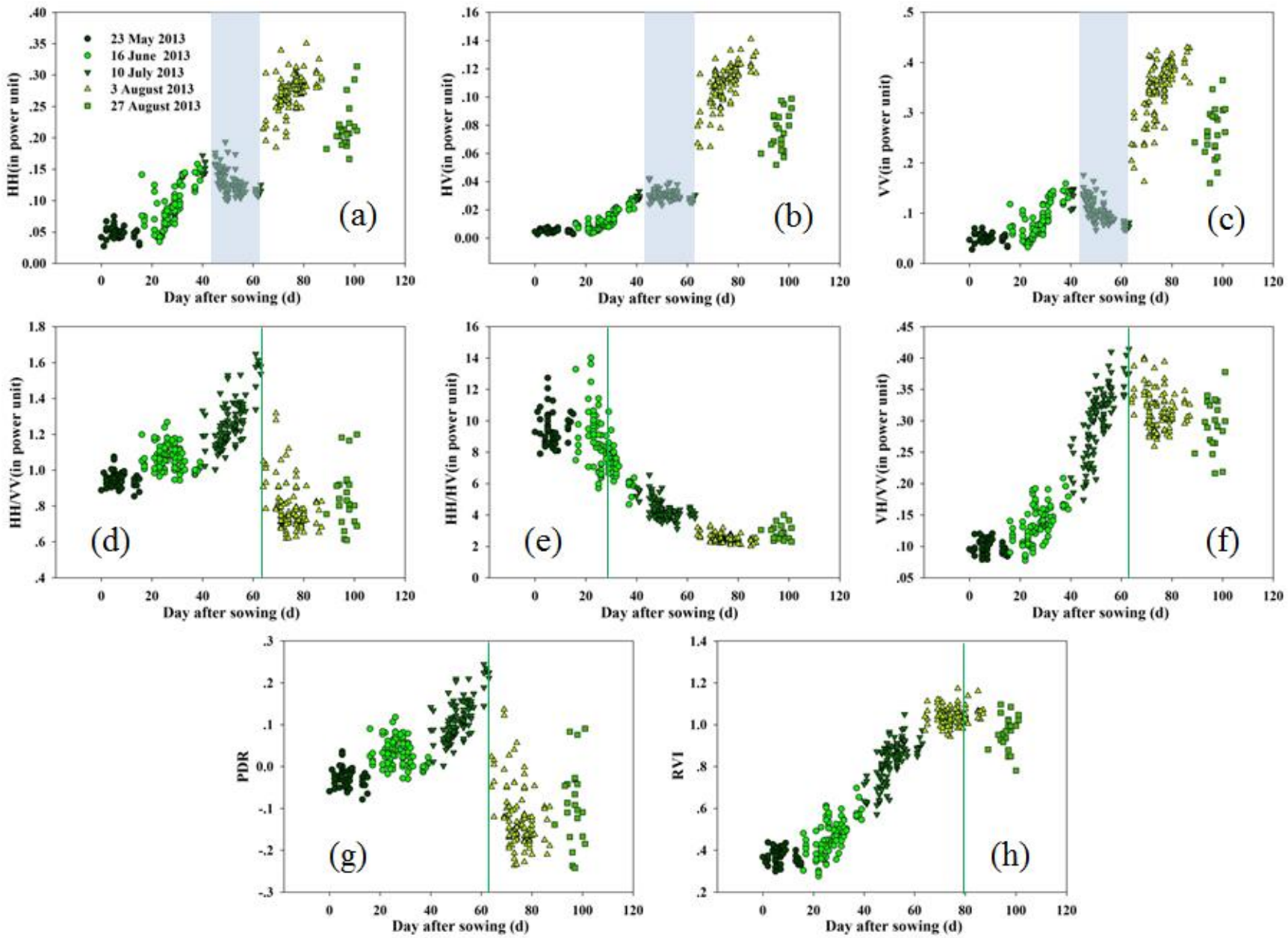
Fig. 6 Temporal profile of different scattering intensity features according to DAS. (a)(b)(c), HH, HV, and VV results for single polarization; $(\mathbf{d})(\mathbf{e})(\mathbf{f})(\mathbf{g}), \mathrm{HH} / \mathrm{VV}, \mathrm{HH} / \mathrm{HV}, \mathrm{VH} / \mathrm{VV}$ and PDR results for dual polarization; (h) RVI results for quad polarization. Blue box in $(\mathbf{a})(\mathbf{b})(\mathbf{c})$ indicates "abnormal" change.

Based on single polarization channel data, three polarization channels, $\mathrm{HH}, \mathrm{HV}$ and $\mathrm{VV}$ were investigated $(\mathrm{VH} \approx \mathrm{VH})$ respectively. The results of the temporal profile of $\mathrm{HH}, \mathrm{HV}$ and $\mathrm{VV}$ scattering intensity (in power unit) over 88 fields are presented in Figure 6(a-c). They show similar trends for HH, HV and VV. At the budding stage (DAS 0 20) (Fig. 2), leaves were just emerging through the soil surface. At this stage, the scattering power remained low because signal contributions come mainly from soil. During the next stage of leaf development (DAS 20 45), the scattering power increased whilst leaves developed and became larger. The leaves had a comparable size to the C-Band wavelength and thus greater vegetation scattering from this increase in leaf area resulted in increase of $\mathrm{HH}, \mathrm{HV}$ and VV. As the crop transitioned to the flowering stage (DAS 45 65), a significant scattering drop was observed, especially for HH and VV (blue box in Fig. 6(a-c)). At the flowering stage, the big leaves began to wither and fall, and the oilseed rape leaves became smaller and fewer. This stage is typically coincident with stem elongation. As a result, leaf area per unit ground area declined and less microwave power was intercepted and scattered, which explained the decrease of backscattering (Yang et al. 2014). When the oilseed rape pods began to emerge (DAS 65 85, filling stage), a large volume of pods created significant multiple scattering and resulted in an increase in the scattering power. When the crop entered into maturation stage (DAS>85) and began to ripen, the plant water content declined (Fig. 4d), thus resulting in more penetration to the soil surface and a decrease in scattering. There was an abrupt increase between the stages 'Flowering' and 'Filling', as shown in Figure 6(a-c). It is hypothesized that this is largely attributed to a rainfall event, which made the backscatter signal increase sharply. This assumption is supported by Figure 5, which shows persistent heavy rain exceeding $180.2 \mathrm{~mm}$ during the previous 7 days. The increase in backscattering was presumably due to increased soil moisture and surface water on the plants after rainfall. The rain effect on backscattering has also been observed in previous studies (Lopez-Sanchez et al. 2012, Wang et al. 2013, Ali et al. 2013).

Based on dual polarization channel data, four typical indicators, $\mathrm{HH} / \mathrm{VV}, \mathrm{HH} / \mathrm{HV}, \mathrm{VH} / \mathrm{VV}$ and PDR, were selected to investigate the capability of dual polarization for predicting crop parameters. The results are shown in Figure 6 (d-g). HH/VV and PDR demonstrate a similar pattern, with increased values as the crop grew before DAS $<60$ then a general sudden decline to low values after DAS $>60$. HH/HV decreased from budding stage (DAS $<20)$ until the filling stage (DAS $>65$ ), then it remained stable at a low value. On Figure 6e, the scatter plots at early growth stages (DAS $<20$ ) showed more scatter, which indicates that $\mathrm{HH} / \mathrm{HV}$ was easily affected by other factors. VH/VV increased with growing days before DAS 60 then decreased slightly after DAS 60.

From these abovementioned results, the temporal profile curves are not monotonic (consistently increasing or decreasing) for either the single or dual polarization indicators, which suggests that all these indicators are susceptible to crop structural changes due to different growing stages. Therefore, it is difficult to identify the scattering response to crop biomass parameters directly and to use simple methods to estimate biomass from either single or dual polarization. 
When quad polarization channel data was available, RVI, a typical indicator exploiting four polarization channels, was chosen to investigate the capability of quad polarization. The results are shown in Figure 6h. The temporal profile has a clear and linear increase before DAS $<80$ and then decreases after DAS 80. In contrast to VH/VV, the inflection point is delayed from DAS=60 to DAS=80, which would allow the use of this crop monitoring index for a wider temporal window. Therefore, full polarization data may have more capability in characterising crop growth, especially when aiming to utilise simple linear models.

\section{Temporal scattering behavior based on polarimetric features}
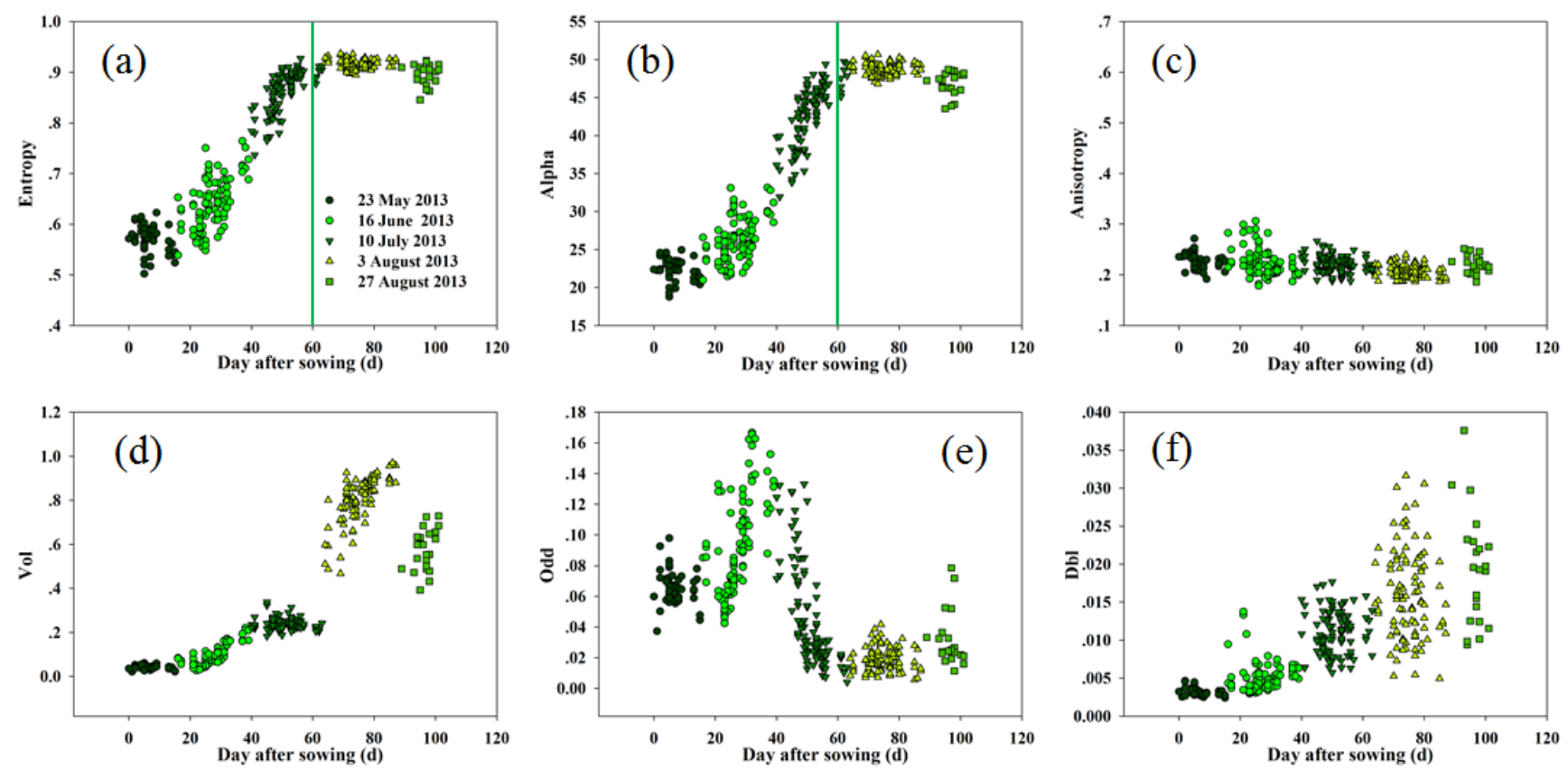

Fig. 7 Temporal profile of different polarimetric features over 88 fields according to DAS. (a)(b)(c), Entropy, Alpha, and Anisotropy results by eigenvalue-based decomposition; (d)(e)(f), Volume, Odd, and Double scattering component results by model-based decomposition.

In addition to scattering intensity, unique polarimetric features can be extracted from fully polarimetric SAR data by target polarimetric decomposition methods. In Figure 7 (a-c), the temporal profile of Entropy, Alpha, and Anisotropy, three classic parameters calculated from the Cloude-Pottier decomposition method over 88 fields are presented. Both Entropy and Alpha increase smoothly with the DAS during the early growth stage $(\mathrm{DAS}<65)$ and then appear to saturate. In light of the physical meaning of Entropy and Alpha, their increase reflects a greater randomness of scattering in the crop. Their saturation can be attributed to a nearly random volume structure of the oilseed rape canopy at its ripening stage, when dense oilseed pods cover the canopy. In this stage, the dominant scattering mechanism was volume scattering (Fig. 7d), which corresponds with Alpha reaching nearly $45^{\circ}$. In addition, Entropy and Alpha have a low sensitivity for oilseed rape biomass in ripening growing stage. Anisotropy remained, however, nearly stable with a value of about 0.22 during the entire growing season, suggesting that relative power of the second and third scattering mechanisms was stable. 
In Figure 7 (d-f), the temporal profile of Volume, Odd, and Double scattering components over 88 fields is shown, three basic parameters calculated from the Freeman-Durden decomposition method. Volume scattering has a similar temporal profile to the HV scattering power, which indicates the scattering contribution from vegetation canopy increased with the DAS during the main growing season, except for the flowering stage (DAS 45 65). Odd scattering was greater in the early growing stages (DAS 20 35), presumably attributed to leaf development, resulting in more surface scattering. Then Odd scattering decreased when the large leaves began to wither. Finally, it remained stable at a low value from DAS $>60$, since less leaves intercepted signals and the scattering mainly resulted from soil, stalks and pods during the ripening stage. Double scattering remained low scattering power during the entire growing season and revealed an increasing trend overall.
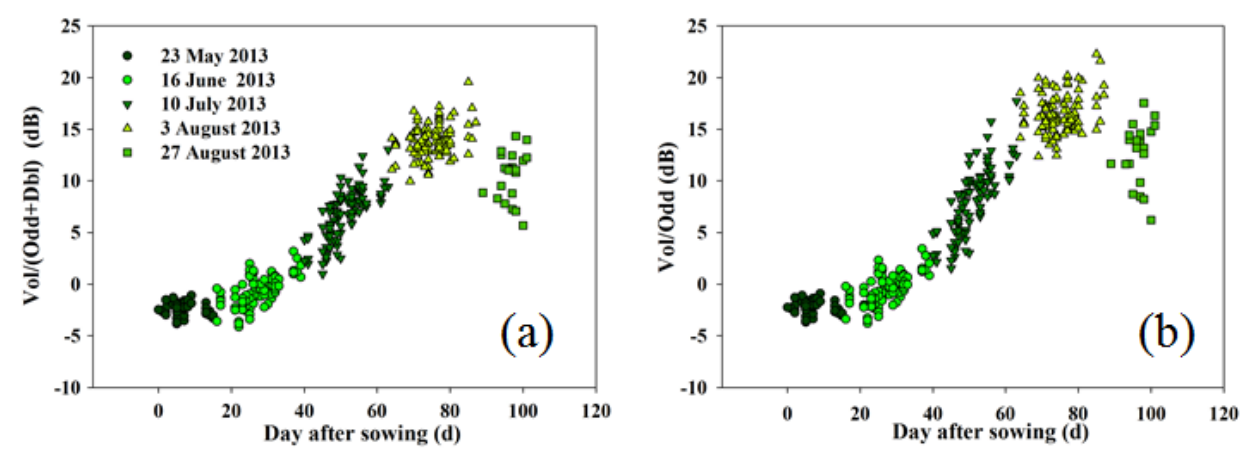

Fig. 8 Temporal profile of two polarimetric indicators over 88 fields, (a) Vol/(Odd+Dbl), (b) Vol/Odd.

The results from polarimetric ratios, $\mathrm{Vol} /(\mathrm{Odd}+\mathrm{Dbl})$ and $\mathrm{Vol} / \mathrm{Odd}$, are presented in Figure 8 . Polarimetric ratio $\mathrm{Vol} /(\mathrm{Odd}+\mathrm{Dbl})$ and $\mathrm{Vol} / \mathrm{Odd}$ have nearly the same temporal profile patterns, where they increased steadily until DAS 80 and then decreased slightly. In contrast to Entropy and Alpha, which reached their saturation points $(\mathrm{DAS}=60)$, these ratios have a delayed saturation point (DAS $>80)$, showing higher sensitivity to plant structure. When DAS $>80$, the crop enters into maturation stage and plant water content decreases sharply (Fig.4d), thus the volume scattering decreases (Yang et al. 2014). In this case, the effective temporal window of the indices covers the main growing stages of oilseed rape.

In fact, when the temporal profile of field observations of biomass and polarimetric ratio was compared (Figure $4 \&$ Figure 8), it was found that there is a highly similar pattern between Vol/Odd or $\operatorname{Vol} /(\mathrm{Odd}+\mathrm{Dbl})$ and fresh or dry biomass when DAS $<80$. Therefore, it is likely that Vol/Odd or $\mathrm{Vol} /(\mathrm{Odd}+\mathrm{Dbl})$ have great potential in estimating crop fresh or dry biomass using radar methods.

\section{Oilseed rape biomass estimation from fully polarization SAR}



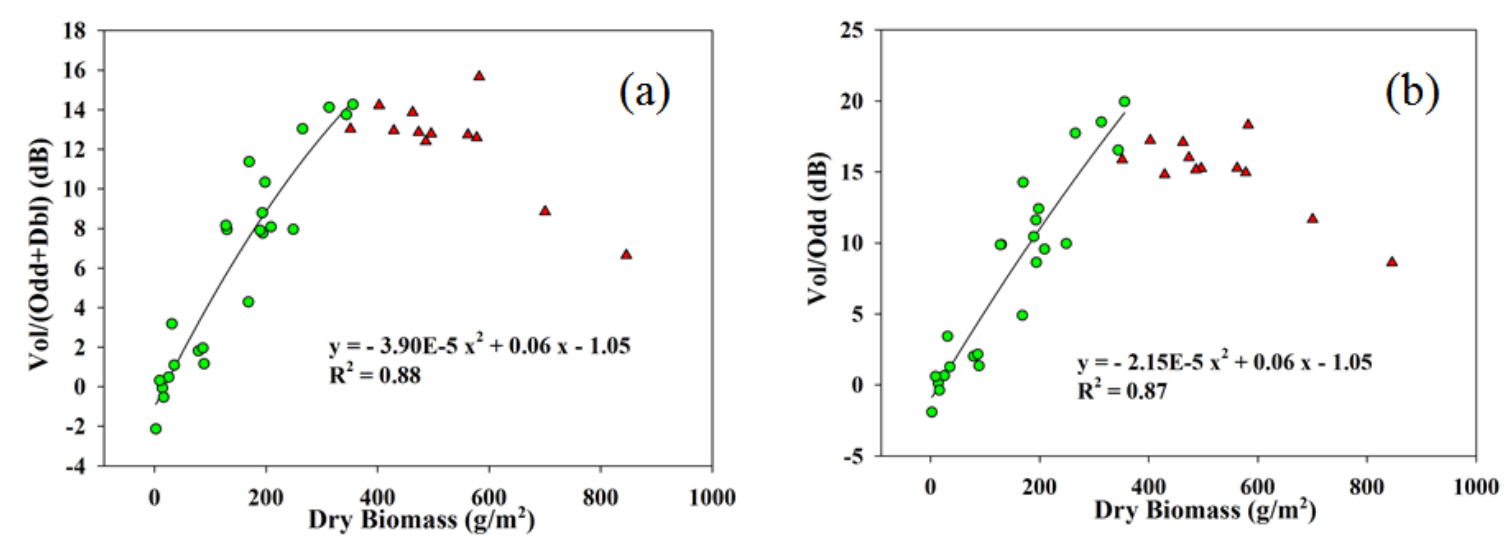

Fig. 9 The relationship between dry biomass and polarimetric indicators, (a) $\mathrm{Vol} /(\mathrm{Odd}+\mathrm{Dbl})$, (b) Vol/Odd. Circles indicate samples with DAS $>75$ and triangles indicate samples with DAS $<75$.
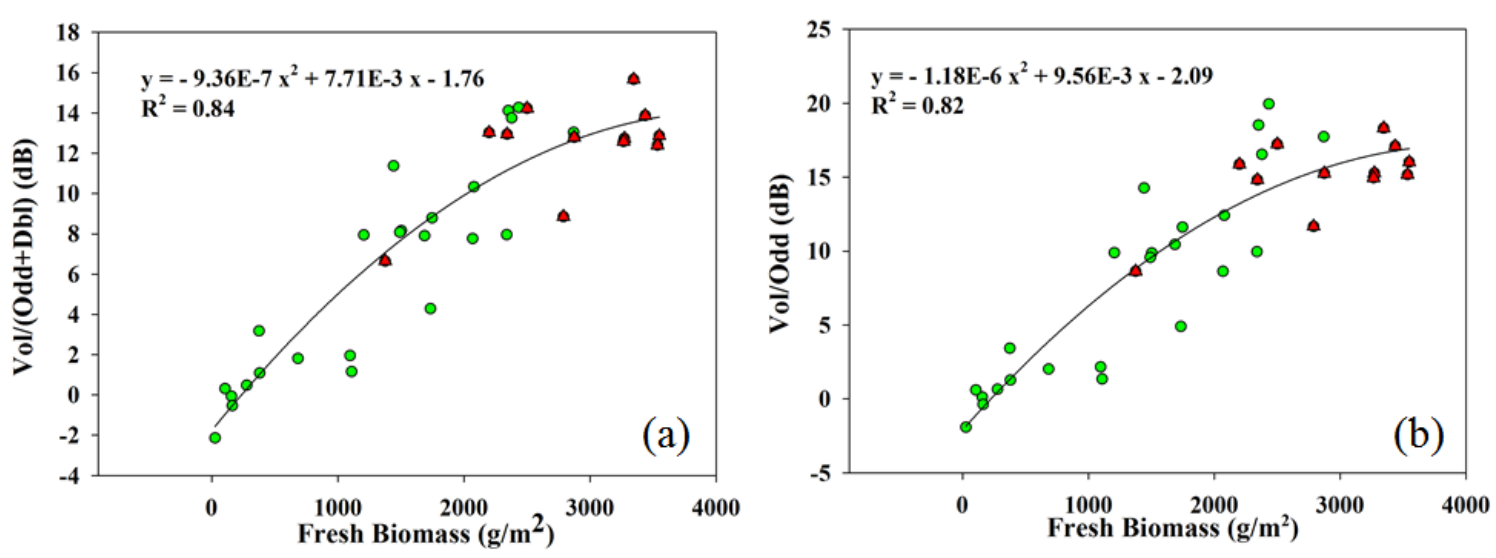

Fig. 10 The relationship between fresh biomass and polarimetric indicators, (a) $\mathrm{Vol} /(\mathrm{Odd}+\mathrm{Dbl}),(\mathbf{b})$ Vol/Odd. Circles indicate samples with DAS $>75$ and triangles indicate samples with DAS $<75$.

Figures 9 and 10 show the relationship between $\mathrm{Vol} /(\mathrm{Odd}+\mathrm{Dbl})$ and $\mathrm{Vol} / \mathrm{Odd}$ and dry and fresh biomass respectively. Circles indicate samples with DAS $>75$ and triangles indicate samples with DAS<75. Vol/ $(O d d+D b l)$ and Vol/Odd have similar performance both for fresh biomass and dry biomass. As shown in Figure 9, there is a good relationship between polarimetric ratios and dry biomass when DAS $<75$, with the coefficient of determination $\left(\mathrm{R}^{2}\right)$ reaching 0.88 and 0.87 when a second order polynomial model is fitted. However, the model does not apply when DAS $>75$. For fields where DAS is $>75$, although the dry biomass increases, the canopy water content decreases, resulting in less scattering power since canopy water content influences radar backscatter greatly. In contrast, as shown in Figure 10, there is a good relationship during the entire growing season for fresh biomass, with $\mathrm{R}^{2}$ reaching 0.84 and 0.82 , respectively. This is because fresh biomass has an inclusion of canopy water content information. Therefore, for the two polarimetric ratios, there is greater capability for monitoring fresh biomass than dry biomass at later stages of oilseed rape development.

Table 3 presents the validation results of biomass estimation by a simple second-order polynomial regression model using Vol/Odd, $\mathrm{Vol} /(\mathrm{Odd}+\mathrm{Dbl})$, VH/VV and RVI, respectively. A leave-one-out crossvalidation method was used. For dry biomass, 24 measurement for DAS $<75$ were used for validation, whilst 36 measurements during the entire growing season were used for fresh biomass validation. According to Table 3, the lowest RMSE and RE was obtained by $\operatorname{Vol} /(\mathrm{Odd}+\mathrm{Dbl})$, with an $\mathrm{R}^{2}$ of 0.85 , 
RMSE of $41.6 \mathrm{~g} / \mathrm{m}^{2}$, RE of $28.5 \%$ for dry biomass, and an $\mathrm{R}^{2}$ of 0.76 , RMSE of $527.4 \mathrm{~g} / \mathrm{m}^{2}$ and RE of $28.6 \%$ for fresh biomass, respectively. Vol/Odd and RVI have an almost equal performance to that of $\mathrm{Vol} /(\mathrm{Odd}+\mathrm{Dbl})$. The dual polarization parameter $\mathrm{VH} / \mathrm{VV}$ did not perform as well when compared to the other indices, with RE of $45.4 \%$ and $41.3 \%$ for dry biomass and fresh biomass, respectively.

Table 3 Comparison of validation results of biomass estimation by different SAR variables

\begin{tabular}{ccccccc}
\hline \multirow{2}{*}{ SAR variables $(\mathbf{x})$} & \multicolumn{3}{c}{ Dry Biomass $(\mathbf{y}, \mathbf{n}=\mathbf{2 4})$} & \multicolumn{3}{c}{ Fresh Biomass $(\mathbf{y}, \mathbf{n}=\mathbf{3 6})$} \\
\cline { 2 - 7 } & $\mathrm{R}^{2}$ & $\mathrm{RMSE}\left(\mathrm{g} / \mathrm{m}^{2}\right)$ & $\mathrm{RE}$ & $\mathrm{R}^{2}$ & $\mathrm{RMSE}\left(\mathrm{g} / \mathrm{m}^{2}\right)$ & $\mathrm{RE}$ \\
\hline Vol/Odd & 0.84 & 42.6 & $29.2 \%$ & 0.75 & 541.2 & $29.4 \%$ \\
$\mathrm{Vol} /(\mathrm{Odd}+\mathrm{Dbl})$ & 0.85 & 41.6 & $28.5 \%$ & 0.76 & 527.4 & $28.6 \%$ \\
$\mathrm{VH} / \mathrm{VV}$ & 0.62 & 66.2 & $45.4 \%$ & 0.51 & 760.4 & $41.3 \%$ \\
$\mathrm{RVI}$ & 0.84 & 42.8 & $29.3 \%$ & 0.76 & 533.5 & $29.0 \%$ \\
\hline
\end{tabular}

\section{Uncertainties in crop biomass retrievals}

Therefore, once the fully polarimetric SAR imagery was acquired at some required date, the polarimetric ratio $\mathrm{Vol} /(\mathrm{Odd}+\mathrm{Dbl})$ can be calculated. Then the dry biomass and fresh biomass of oilseed rape in the covering area can be inverted based on the second-order polynomial regression model (the equation in Fig. 9 and Fig. 10). In practical application, the parameters of the second-order polynomial regression model will be calibrated by a few in-situ samples in a different year and a different region. Then the biomass will be estimated from the calibrated model for site-specific management.

However, as shown in Table 3, the accuracy of biomass estimation (RE, Relative Error) presented in this study is not so high. Only a simple regression model was used in this study, since the aim is to reveal the potential capability of fully polarimetric SAR data in biomass estimation. Other complex methods, such as PLS (partial least squares), multistep regression, random forest, and support vector machine methods could be used, and it can be expected that the accuracy will be improved greatly (Jin et al. 2015, Jia et al. 2014).

Moreover, biomass measurement error is a significant error source which influences the final model accuracy. Since ground biomass measurements have a lot of uncertainty, e.g. sample representativeness and subjective procedures and observation errors are inevitable. Plant height is easier to measure and thus potentially more accurate than biomass. Figure 11 presents the relationships between height and polarimetric parameters including $\mathrm{Vol} /(\mathrm{Odd}+\mathrm{Dbl})$, Vol/Odd, RVI, Alpha, Entropy and VH/VV. Better relationships can be observed than with biomass. 

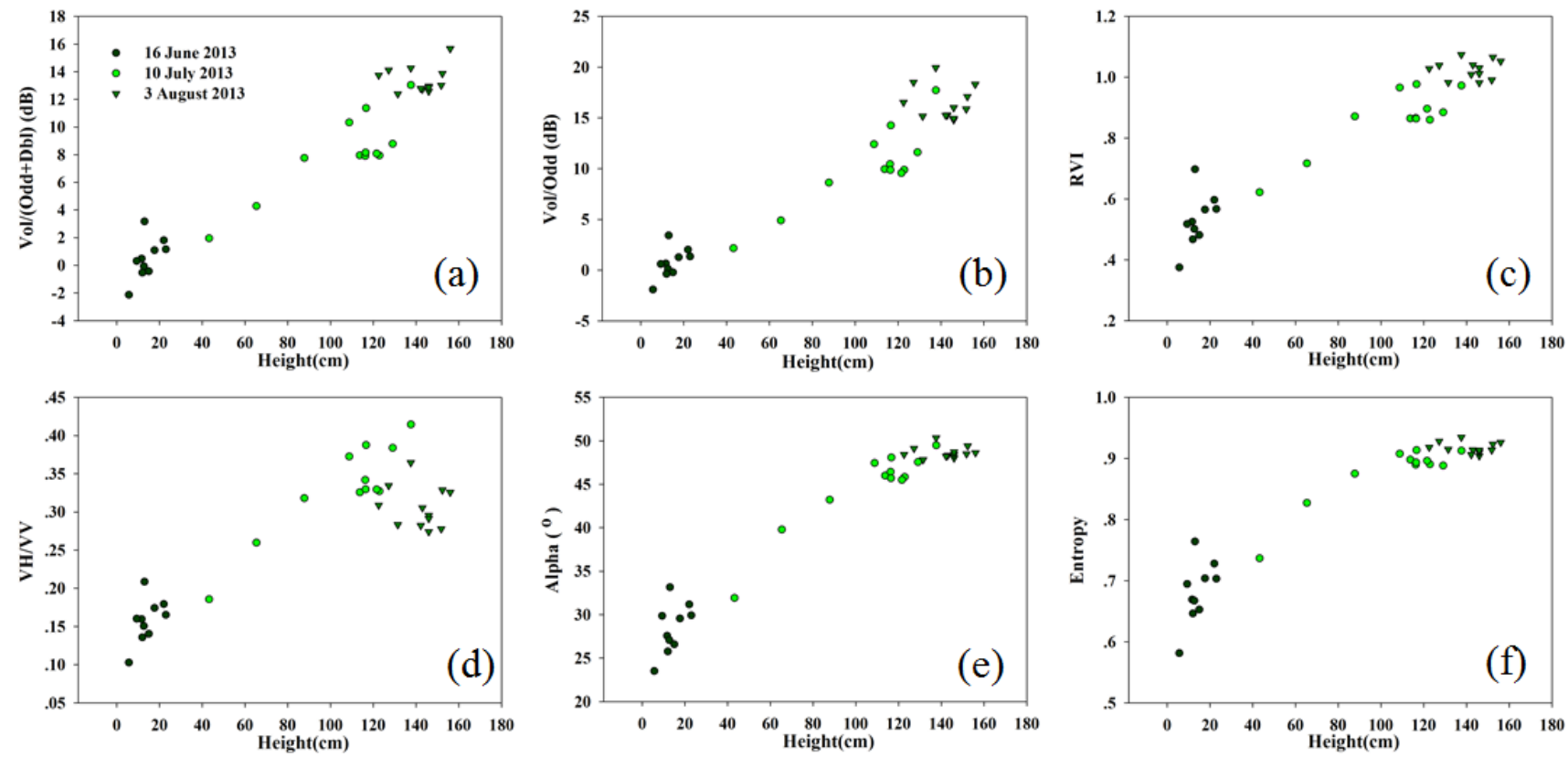

Fig. 11 The relationship between crop height and different SAR indicators

Understanding of the interaction between microwave radar signals and crop biomass needs to be further researched. Biomass is just one of the factors that influence scattering. Microwaves respond to the structural attributes of vegetation, including size, shape and orientation of leaves, stems, and fruits, the planting density and row direction. The dielectric properties of the vegetation canopy, that is canopy water content, also influence radar backscatter. When the crop structure and canopy water content both vary as crops grow, the response becomes more complex. When crops enter the ripening stage, the canopy water content changes rapidly, and it is then challenging to monitor biomass. Fortunately, the crop yield has been largely determined before ripening stage, when it is not so important for in-season site-specific management.

To the best of the authors' knowledge, no literature has previously reported these simple and clear temporal patterns for oilseed rape biomass, which highlights the feasibility of monitoring crop growth parameters by simple methods, with SAR data (especially with polarimetric features). While most studies have presented the temporal profile based on limited fields and limited temporal observations (Lopez-Sanchez et al. 2014, 2012, Li et al. 2012, Kim et al. 2014), this study provided a more comprehensive temporal profile analysis based on extensive fields (88 fields) and near-continuous observation frequency (85 observation dates). Wiseman et al. (2014) investigated the response of different parameters from RADARSAT-2 data against dry biomass of canola, corn, soybean and spring wheat. Their study was only over a 6-week period, and only revealed some parameters to have a strong relationship with crop biomass. Wiseman et al. (2014) were therefore unable to achieve a quantitative biomass estimation result. Jin et al. (2015) and Gao et al. (2013) estimated the biomass of winter wheat and maize, respectively. Although more complex inversion models (partial least squares method and multistep regression method) were used and optical data were combined, their results (dry biomass, RMSE $146.3 \mathrm{~g} / \mathrm{m}^{2}$ ) were inferior to the results presented here (dry biomass, RMSE $41.6 \mathrm{~g} / \mathrm{m}^{2}$ ). Jia et al. $(2014,2013)$ estimated the biomass of rice with ground-based radar scatterometer and neural network 
methods were used, based on Monte Carlo simulations. However, they obtained a result of fresh biomass estimation (RMSE $816.0 \mathrm{~g} / \mathrm{m}^{2}$ ) while these results are more promising (RMSE $527.4 \mathrm{~g} / \mathrm{m}^{2}$ ).

It should be noted that, when GDDs were used as the timeline, a similar temporal pattern could be observed with the results of DAS. Due to limited space, the results of GDDs will not be presented in this study.

However, further validation and more quantitative research is required to improve the understanding of the interaction between microwave radar signals and crop biomass and to improve estimation accuracy. More careful study should be conducted to analyze the main influence factors of biomass estimation model, i.e. planting direction, soil moisture, crop cultivars, phenological stage, plant water content and terrain slope. These factors should be incorporated into building a more general biomass estimation model with strong mechanism and high accuracy. In addition, the biomass estimation model in this study is built upon multi-temporal data. However, the estimation model using single date SAR data should be further investigated and validated.

\section{Conclusions}

This study investigated the potential capability of fully polarimetric SAR data in estimating above ground biomass of oilseed rape. The necessity of polarimetric information was firstly proved in quantitative crop monitoring by SAR data. The advantage of the full polarization SAR data over single polarization and dual polarization SAR data were investigated. The temporal profile of ground measurements was compared with the temporal scattering behavior of some SAR features, including backscattering coefficient of $\mathrm{HH}, \mathrm{HV}$ and VV from single polarization, $\mathrm{HH} / \mathrm{VV}, \mathrm{HH} / \mathrm{HV}, \mathrm{VH} / \mathrm{VV}$ and PDR from dual polarization, and Entropy, Alpha, RVI, Vol/(Odd+Dbl) and Vol/Odd from full polarization. It was found that, when full polarimetric SAR data were used, a simpler model, a higher saturation point and better accuracy could be achieved in biomass estimation of oilseed rape, in contrast to using single or dual polarization SAR data. The results highlighted the importance and value of polarimetry information in quantitative crop monitoring.

Moreover, the polarimetric features $\mathrm{Vol} /(\mathrm{Odd}+\mathrm{Dbl})$, Vol/Odd and RVI showed significant potential in estimating the biomass of oilseed rape. The lowest RMSE and RE were obtained by $\mathrm{Vol} /(\mathrm{Odd}+\mathrm{Dbl})$ using a simple second-order polynomial regression model, with an $\mathrm{R}^{2}$ of 0.85 , RMSE of $41.6 \mathrm{~g} / \mathrm{m}^{2}, \mathrm{RE}$ of $28.5 \%$ for dry biomass, and an $\mathrm{R}^{2}$ of 0.76 , RMSE of $527.4 \mathrm{~g} / \mathrm{m}^{2}$ and RE of $28.6 \%$ for fresh biomass, respectively. This study provides guidelines for in-season crop growth parameter monitoring with SAR data, further improving crop monitoring capability in cloudy conditions.

Acknowledgments This work was supported by Open Research Fund of Digital Earth Science, Institute of Remote Sensing and Digital Earth, Chinese Academy of Sciences (No. 2015LDE003), National Natural Science Foundation of China (61661136003), and 03-Y20A11-9001-15/16.

\section{References}

Ahamed, T., Tian, L., Zhang, Y., \& Ting, K. C. (2011). A review of remote sensing methods for biomass feedstock production. Biomass and Bioenergy, 35(7), 2455-2469. 
Ali, I., Schuster, C., Zebisch, M., Forster, M., Kleinschmit, B., \& Notarnicola, C. (2013). First results of monitoring nature conservation sites in alpine region by using very high resolution (VHR) X-band SAR data. IEEE Journal of Selected Topics in Applied Earth Observations and Remote Sensing, 6(5), 2265-2274.

Attema, E. P. W., \& Ulaby, F. T. (1978). Vegetation modeled as a water cloud. Radio science, 13(2), 357-364.

Baghdadi, N., Boyer, N., Todoroff, P., Elhajj, M., \& Bégué, A. (2009). Potential of SAR sensors TerraSAR-X, ASAR/ENVISAT and PALSAR/ALOS for monitoring sugarcane crops on reunion island. Remote Sensing of Environment, 113(8), 1724-1738.

Bendig, J., Bolten, A., Bennertz, S., Broscheit, J., Eichfuss, S., \& Bareth, G. (2014). Estimating biomass of barley using crop surface models (CSMs) derived from UAV-based RGB imaging. Remote Sensing, 6(11), 1039510412.

Bériaux, E., Lucau-Danila, C., Auquiere, E., \& Defourny, P. (2013). Multiyear independent validation of the water cloud model for retrieving maize leaf area index from SAR time series. International Journal of Remote Sensing, 34(12), 4156-4181.

Bériaux, E., Waldner, F., Collienne, F., Bogaert, P., \& Defourny, P. (2015). Maize Leaf Area Index Retrieval from Synthetic Quad Pol SAR Time Series Using the Water Cloud Model. Remote Sensing, 7(12), 16204-16225.

Cable, J. W., Kovacs, J. M., Jiao, X., \& Shang, J. (2014). Agricultural monitoring in northeastern Ontario, Canada, using multi-temporal polarimetric RADARSAT-2 data. Remote Sensing, 6(3), 2343-2371.

Cloude, S., Pottier, E. (1997) An entropy based classification scheme for land applications of polarimetric SAR. IEEE Transactions on Geoscience and Remote Sensing, 35 (1), 68-78.

Cloude, S. (2009). Polarisation: applications in remote sensing. Oxford, UK: Oxford University Press.

FAO, 2013. FAOSTAT Database. Food and Agriculture Organization of the United Nations, Rome. Available at http://faostat.fao.crg (Last accessed on March 10, 2016).

Fontanelli, G., Paloscia, S., Zribi, M., \& Chahbi, A. (2013). Sensitivity analysis of X-band SAR to wheat and barley leaf area index in the Merguellil Basin. Remote Sensing Letters, 4(11), 1107-1116.

Freeman, A., Durden, S.L. (1998) A three-component scattering model for polarimetric SAR data. IEEE Transactions on Geoscience and Remote Sensing, 36(3), 963-973.

Gao, S., Niu, Z., Huang, N., \& Hou, X. (2013). Estimating the Leaf Area Index, height and biomass of maize using HJ-1 and RADARSAT-2. International Journal of Applied Earth Observation and Geoinformation, 24, $1-8$.

Gens, R., Atwood, D. K., \& Pottier, E. (2013). Geocoding of polarimetric processing results: Alternative processing strategies. Remote Sensing Letters, 4(1), 38-44.

Hosseini, M., McNairn, H., Merzouki, A., \& Pacheco, A. (2015). Estimation of Leaf Area Index (LAI) in corn and soybeans using multi-polarization C-and L-band radar data. Remote Sensing of Environment, 170, 7789.

Hunt Jr, E. R., Cavigelli, M., Daughtry, C. S., Mcmurtrey III, J. E., \& Walthall, C. L. (2005). Evaluation of digital photography from model aircraft for remote sensing of crop biomass and nitrogen status. Precision Agriculture, 6(4), 359-378.

Inoue, Y., Sakaiya, E., \& Wang, C. (2014). Capability of C-band backscattering coefficients from high-resolution satellite SAR sensors to assess biophysical variables in paddy rice. Remote Sensing of Environment, 140, 257-266.

Jia, M., Tong, L., Chen, Y., Wang, Y., \& Zhang, Y. (2013). Rice biomass retrieval from multitemporal groundbased scatterometer data and RADARSAT-2 images using neural networks. Journal of Applied Remote Sensing, 7(1), 073509-073509.

Jia, M., Tong, L., Zhang, Y., \& Chen, Y. (2014). Rice Biomass Estimation Using Radar Backscattering Data at S- 
band. IEEE Journal of Selected Topics in Applied Earth Observations and Remote Sensing, 7(2), 469-479.

Jiao, X., McNairn, H., Shang, J., Pattey, E., Liu, J., \& Champagne, C. (2011). The sensitivity of RADARSAT-2 polarimetric SAR data to corn and soybean leaf area index. Canadian Journal of Remote Sensing, 37(1), 6981.

Jin, X., Yang, G., Xu, X., Yang, H., Feng, H., Li, Z., et al. (2015). Combined Multi-Temporal Optical and Radar Parameters for Estimating LAI and Biomass in Winter Wheat Using HJ and RADARSAR-2 Data. Remote Sensing, 7(10), 13251-13272.

Kim, Y., Jackson, T., Bindlish, R., Hong, S., Jung, G., \& Lee, K. (2014). Retrieval of wheat growth parameters with radar vegetation indices. IEEE Geoscience and Remote Sensing Letters, 11(4), 808-812.

Kross, A., McNairn, H., Lapen, D., Sunohara, M., \& Champagne, C. (2015). Assessment of RapidEye vegetation indices for estimation of leaf area index and biomass in corn and soybean crops. International Journal of Applied Earth Observation and Geoinformation, 34, 235-248.

Lee, J. S., \& Pottier, E. (2009). Polarimetric radar imaging: from basics to applications. New York, USA: CRC press, Taylor\&Francis Group.

Li, K., Brisco, B., Yun, S., \& Touzi, R. (2012). Polarimetric decomposition with RADARSAT-2 for rice mapping and monitoring. Canadian Journal of Remote Sensing, 38(2), 169-179.

Lin, H., Chen, J., Pei, Z., Zhang, S., \& Hu, X. (2009). Monitoring sugarcane growth using ENVISAT ASAR data. IEEE Transactions on Geoscience and Remote Sensing, 47(8), 2572-2580.

Lopez-Sanchez, J. M., \& Ballester-Berman, J. D. (2009). Potentials of polarimetric SAR interferometry for agriculture monitoring. Radio Science, 44(2), 1-20.

Lopez-Sanchez, J. M., Cloude, S. R., \& Ballester-Berman, J. D. (2012). Rice phenology monitoring by means of SAR polarimetry at X-band. IEEE Transactions on Geoscience and Remote Sensing, 50(7), 2695-2709.

Lopez-Sanchez, J. M., Vicente-Guijalba, F., Ballester-Berman, J. D., \& Cloude, S. R. (2014). Polarimetric response of rice fields at C-band: Analysis and phenology retrieval. IEEE Transactions on Geoscience and Remote Sensing, 52(5), 2977-2993.

McNairn, H., \& Brisco, B. (2004). The application of C-band polarimetric SAR for agriculture: a review. Canadian Journal of Remote Sensing, 30(3), 525-542.

McNairn, H., Kross, A., Lapen, D., Caves, R., \& Shang, J. (2014). Early season monitoring of corn and soybeans with TerraSAR-X and RADARSAT-2. International Journal of Applied Earth Observation and Geoinformation, 28, 252-259.

McNairn, H., Shang, J., Jiao, X., \& Champagne, C. (2009). The contribution of ALOS PALSAR multipolarization and polarimetric data to crop classification. IEEE Transactions on Geoscience and Remote Sensing, 47(12), 3981-3992.

Paloscia, S. (2002). A summary of experimental results to assess the contribution of SAR for mapping vegetation biomass and soil moisture. Canadian Journal of Remote Sensing, 28(2), 246-261.

Qi, Z., Yeh, A. G. O., Li, X., Xian, S., \& Zhang, X. (2015). Monthly short-term detection of land development using RADARSAT-2 polarimetric SAR imagery. Remote Sensing of Environment, 164, 179-196.

Raoofi, F. \& Javadi, S. (2014). Modeling phonological stages of Artemisia sieberi using GDD. International Journal of Biosciences, 4(1), 225-230.

Ren, T., Li, H., Lu, J., Bu, R., Li, X., Cong, R., et al. (2015). Crop rotation-dependent yield responses to fertilization in winter oilseed rape (Brassica napus L.). The Crop Journal, 3(5), 396-404.

Singh, D. (2006). Scatterometer performance with polarization discrimination ratio approach to retrieve crop soybean parameter at X-band. International Journal of Remote Sensing, 27(19), 4101-4115.

Tanase, M. A., Panciera, R., Lowell, K., Tian, S., Hacker, J. M., \& Walker, J. P. (2014). Airborne multi-temporal 
L-band polarimetric SAR data for biomass estimation in semi-arid forests. Remote Sensing of Environment, 145, 93-104.

Tilly, N., Aasen, H., \& Bareth, G. (2015). Fusion of Plant Height and Vegetation Indices for the Estimation of Barley Biomass. Remote Sensing, 7(9), 11449-11480.

Wang, X., Ge, L., \& Li, X. (2013). Pasture Monitoring Using SAR with COSMO-SkyMed, ENVISAT ASAR, and ALOS PALSAR in Otway, Australia. Remote Sensing, 5(7), 3611-3636.

Wiseman, G., McNairn, H., Homayouni, S., \& Shang, J. (2014). RADARSAT-2 Polarimetric SAR Response to Crop Biomass for Agricultural Production Monitoring. IEEE Journal of Selected Topics in Applied Earth Observations and Remote Sensing, 7(11), 4461-4471.

Yang, H., Chen, E., Li, Z., Zhao, C., Yang, G., Pignatti, S., et al. (2015). Wheat lodging monitoring using polarimetric index from RADARSAT-2 data. International Journal of Applied Earth Observation and Geoinformation, 34, 157-166.

Yang, H., Li, Z., Chen, E., Zhao, C., Yang, G., Casa, R., et al. (2014). Temporal polarimetric behavior of oilseed rape (Brassica napus L.) at C-band for early season sowing date monitoring. Remote Sensing, 6(11), 1037510394.

Zhang, L., Guo, H., \& Li, X. (2012). Simulation analysis on the relationship between the leaf area index and polarimetric parameters of crops. International Journal of Digital Earth, 5(4), 319-337.

Zhang, Y., Liu, X., Su, S., \& Wang, C. (2014). Retrieving canopy height and density of paddy rice from RADARSAT-2 images with a canopy scattering model. International Journal of Applied Earth Observation and Geoinformation, 28, 170-180. 